\title{
The Impact of Corporate Social Responsibility on Share Price: A Systematic Review and Bibliometric Analysis
}

\author{
HAMAD RAZA ${ }^{1}$, SYED MUHAMMAD AHMAD HASSAN GILLANI ${ }^{2}$, MUHAMMAD TAYYAB \\ KASHIF ${ }^{3}$, NOHMAN KHAN ${ }^{4}$ \\ ${ }^{1}$ Azman Hashim International Business School (AHIBS), UNIVERSITI TEKNOLOGI MALAYSIA (UTM), MALAYSIA. \\ E-mail: hamad_raza@hotmail.co.uk \\ ${ }^{2}$ Azman Hashim International Business School (AHIBS), UNIVERSITI TEKNOLOGI MALAYSIA (UTM), MALAYSIA. \\ ${ }^{3}$ Lyallpur Business School, GOVERNMENT COLLEGE UNIVERSITY FAISALABAD, PAKISTAN. \\ ${ }^{4}$ UniKL Business School, UNIVERSITI KUALA LUMPUR, MALAYSIA.
}

\begin{abstract}
This article presents the systematic literature review of 91 published research papers on the impact of corporate social responsibility (CSR) on share price between 2014 and 2019. The results indicate that the interest in the topic of CSR and its effect on firm value in terms of share price has significantly grown throughout this period. The findings show that the literature can be categorized based on three main methods of the studies: whether the paper seeks to focus on exploratory research (Qualitative); whether they seek to emphasize the objective measurement by performing mathematical, statistical or numerical analysis of data gathered (Quantitative); or articles that seek to draw conclusions from previously published studies (Review). This article attempts to cover the systematic review and bibliometric analysis by presenting findings through analysis on selected articles, which highlight some possible gaps and opportunities in the literature along with a scope of directions for future research.
\end{abstract}

Keywords: CSR, Systematic, Share Price, Review, Bibliometric

JEL Classification: G3, G1 


\section{Introduction}

A corporation prime goal is to maximise its shareholder's wealth and this objective can be achieved by maximising the value of an organization (Van Horne., 2002). In the course of attaining this desirable goal of increasing company value, company's operations, activities and good corporate governance practices play an important role. One of the firm's activities that are becoming more and more popular in the business community all over the world is CSR. During the past decade, the attention towards CSR has grown among academics, investors, practitioners and firms. According to the report presented by Economist Intelligence Unit (2005), CSR is assumed as an "important or central" attention for both investors (81\%) and managers (86\%) (Nguyen, Kecskés, \& Mansi, 2017).

Corporate Social Responsibility permits a company to react to the developing needs of society, whether they are related to environmental, social or economic issues. The company practising CSR activities has many advantages including an increase in its financial performance (Dornean \& Oanea, 2017). According to Dornean and Oanea (2016), the average price and average dividend of companies practising CSR are higher in comparison to the companies not involved in CSR practices. In addition, their study also determined that share price is the key market driver for the firm performing CSR activities and has a significant impact. However, Raza, Ramakrishnan, Gillani, and Ahmad (2019) mention that the influence of corporate sustainability practices including CSR exerts tremendous pressure on the firm operations and financial performance, which affects the share price of the firm. Additionally, Hao, Qi, and Wang (2018) stated that the adoption of CSR can affect the financial and accounting behaviour and market performance (share price) of a firm. A huge number of studies in growing literature have examined the relationship between corporate social responsibility and firm accounting, financial or market performance (Walsh \& Margolis, 2001; Lee \& Faff, 2009; El Ghoul, Guedhami, Kwok, \& Mishra, 2011; Goss \& Roberts, 2011; Kim, Park, \& Wier, 2012; Kim \& Statman, 2012; Hao et al., 2018; Myšková \& Hájek, 2019; Prieto, Shin, Lee, \& Lee, 2020). Yet, comparatively little is known about the connection between corporate social responsibility and share price because whether CSR has a positive or negative influence on value is still debatable and inconclusive (Derwall, Koedijk, \& Ter Horst, 2011; Hao et al., 2018, Khan, N., \& Qureshi, M. 2020).

This systematic review and bibliometric analysis article intents to investigate the literature on the link between CSR and share price or firm value. This article will explore distinct natures of studies comprising of diverse research perspectives and link among them. Lastly, the article will conclude to offer propositions and identify opportunities for future research. The article is structured as follows. The next section represents the research method of the systematic literature review and portrays all the steps taken. The third section summarizes and categorizes the distinct type of studies related to the topic of this paper. The fourth section then presents a discussion of results based on the analysis undertaken. Finally, the article concludes by pointing out the gaps and opportunities in the literature that can be taken into consideration for future research.

\section{Methodology}

Literature review intent to map and assess the body of literature to highlight prospective research opportunities and point out the boundaries of knowledge (Tranfield, Denyer, \& Smart, 2003). The systematic literature review is usually conducted based on an iterative cycle of outlining suitable protocols, which includes keywords search, literature searching and accomplishing the analysis (Saunders, Lewis, \& Thornhill, 2009). As described in the above section, although there are various studies that try to assess the connection between CSR and market performance (share price) of the firms, however, there is no review that summed up all these studies and provides a deeper insight to this vital research area. Therefore, this section represents the entire procedure of systematic review followed in this paper. 


\subsection{Systematic review}

The crucial step in every systematic review is defining the research question, which will help in achieving their aim. The first step involves selecting the most suitable search method i.e. digital sources (libraries and indexing systems) and the identification of the search terms. This study selected Scopus as a digital source for review of the literature and the keywords used to find out the titles and abstracts of the papers in this literature review are: "Corporate Social Responsibility" AND "Stock Price*", "Corporate Social Responsibility" AND "Share Price*", "Corporate Social Responsibility" AND "Firm Value", "Corporate Social Responsibility" AND "Shareholders Wealth".

Table 1 Inclusion and exclusion criteria for the refinement

\begin{tabular}{|l|l|}
\hline \multicolumn{1}{|c|}{ Inclusion Criteria } & \multicolumn{1}{c|}{ Exclusion Criteria } \\
\hline - $\begin{array}{l}\text { Papers published from the year 2014 to } 2019 \\
\text { were included. }\end{array}$ & • Non-English language article was excluded. \\
- $\begin{array}{l}\text { Papers title related to the relationship between } \\
\text { CSR and share price (firm value) was selected. } \\
\text { - } \begin{array}{l}\text { Bnpublished working articles were eliminated. } \\
\text { Only papers from Scopus digital source were } \\
\text { included. }\end{array}\end{array}$ & - Missing record papers were also excluded. \\
\hline
\end{tabular}

In order to prevent receiving a massive amount of papers as a search outcome, only papers published from the year 2014 to 2019 were included. The initial search attempts to identify 269 papers in Scopus database and the result of above keyword search were saved in CSV format for information related to all identified papers such as authors' name, article title, name of the journal, volume and issue number, affiliation, keyword, abstract and document type. There are a few papers, which were overlap by using the above keywords to search for papers. After removing the duplicates and missing record like authors' name/journal, 255 papers remained.

Figure 1 PRISMA flowchart for the paper selection process
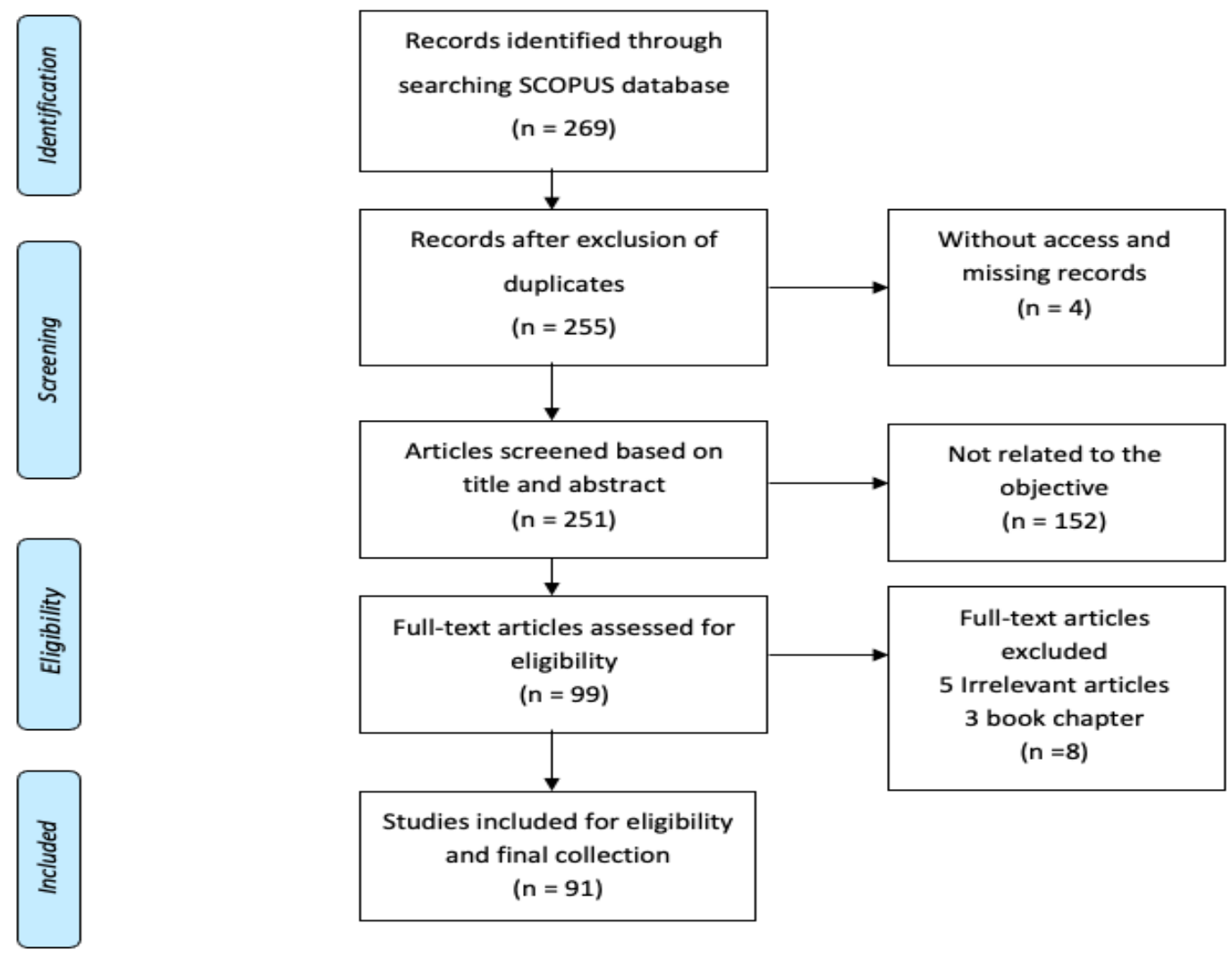

The second step involves screening the papers based on titles and abstracts after applying inclusion and exclusion criteria as mention in Table 1 and 152 studies were eliminated, which did not match the objective of the study. In particular, studies focusing on the link between CSR and share price are 
included. The final step contains reviewing the full-text of these papers and 91 papers were selected for classification and analysis as shown in Figure 1. These all steps for systematic review have been performed in accordance with the PRISMA statement, which comprises of these steps already, explain above (Liberati et al., 2009).

\subsection{Bibliometric Maps}

In this review, we used VOS-viewer (version 1.6.15), which is a bibliometric mapping visualization software instrument. According to Van Eck and Waltman (2020), the developers of this software, "it can be used to create maps based on network data and for visualizing and exploring these maps". The Scopus database sheet of the included studies is exported to VOSviewer software. The items in this study, which are an interest of concern are countries and keywords of the author. The association can occur between any pair of items, a relationship or link between two items. Each link has a strength that reflects numbers with a positive value. The greater the value, the higher the connection. The strength of association between one country to another country indicates the number of publications co-authored by two linked countries for co-authorship analysis. Similarly, the author's keyword link strength reveals the number of publications in which two keywords are used in the co-occurrence analysis.

\section{Classification of papers}

The systematic literature review of this paper depicts three main groups of articles (i) Qualitative (ii) Quantitative (ii) Review. The papers are classified into these categories by evaluating the abstract of the articles and distribution of each group is presented in Figure 2. The first group refers to the studies that seek to focus on exploratory research. These are mostly the type of studies, which are conducted for a problem that has not been studied more clearly. The nature of qualitative studies is inductive because researchers first select a generic topic and collect information for the formation of the hypothesis. The second group they seek to emphasize the objective measurement by performing mathematical, statistical or numerical analysis of data collected. The nature of quantitative research is deductive, where researcher forms the hypothesis and then collects data to inspect the problem and after the analysis is performed, conclusions are shared to identify that whether hypotheses are true or false. The last group includes papers that seek to draw conclusions from previously published studies. The researcher tries to sum up the present state of understanding on the topic, rather than presenting new facts or analysis. The classification of papers based on research method depicts a clear lead of quantitative method publications over qualitative and literature review papers. This indicates that qualitative and review papers are rare on the topic link between CSR and share price.

Figure 2 Distribution of papers based on classification

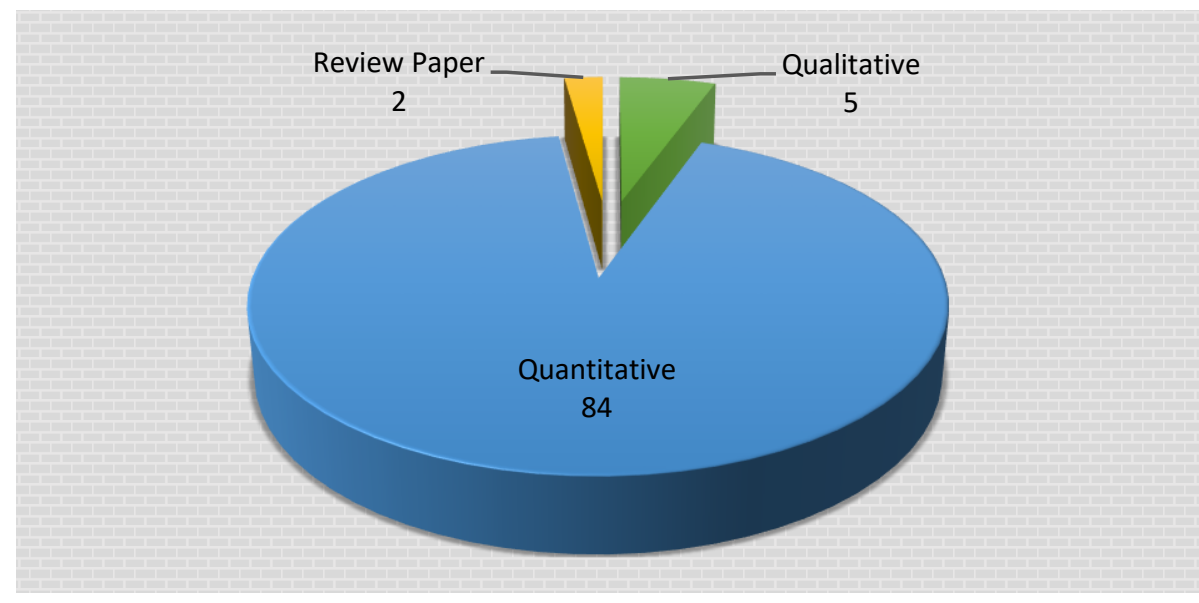




\section{Results and analysis}

In this section, the analysis is performed based on 91 selected articles according to publication year, journal, country and nature of papers along with bibliometric analysis. This analysis will offer an understanding of the topic, key trends and highlight future research gaps and opportunities.

\subsection{Distribution based on publication year}

The evolution of a number of paper publications per year from 2014 to 2019 is shown in Figure 3. The distribution of publications by year-wise demonstrates a steady and gradual increase in studies during this time period and reaching the highest in 2018. It can be seen that most of the papers are published in recent years, specifically from 2016 to 2019, indicating 87\% of the total articles, which shows an increasing trend over the years. This suggests that the topic of CSR and its effect on share price remains a significant area and is likely to remain in years to come because corporate organization have recognized that involving in CSR activities can be beneficial for market value and share of the firm and can play an important role in the society.

Figure 3 Distribution based on publication year

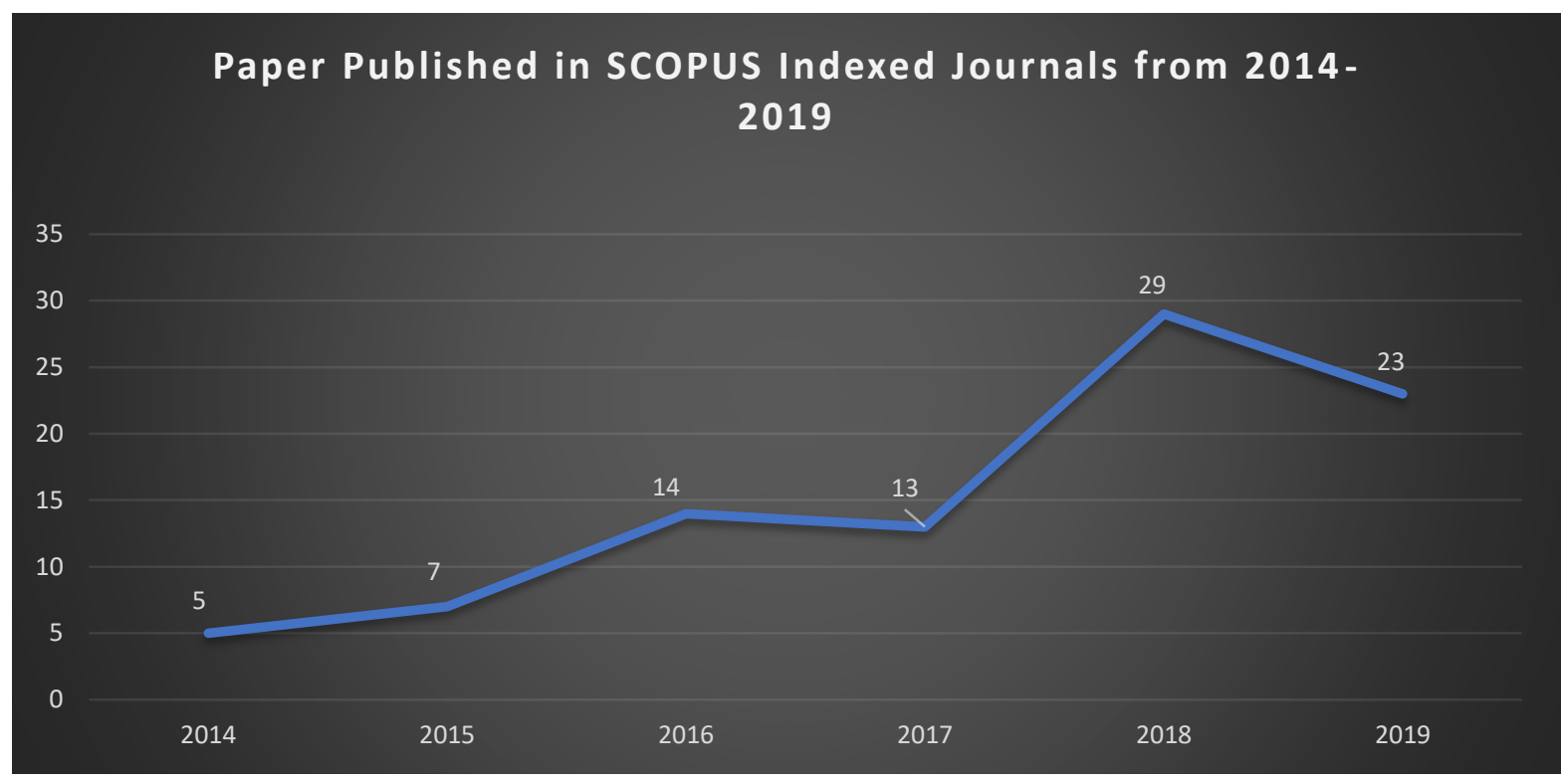

\subsection{Distribution based on journal}

The percent distribution of the journal shows that which journal publishes the most papers on the topic link between CSR and share price as observed in Table 2. The journal, which most often addresses this issue, is Sustainability (Switzerland) having 34\% (14 articles). Notably, almost $54 \%$ of all papers examined were published in just two journals. The other residual papers were published over 59 journals (one journal having three papers, eight journals having two papers each and fifty journals having one paper each).

However, the quantity of papers published per journal is alone not a good benchmark to evaluate the journals because different papers have different effects. Thus, the impacts of journal papers on the following studies must be kept in mind while interpreting the above outcomes. To counter this issue, we use citations reported in the Scopus database for each journal. According to Hanafizadeh and Khedmatgozar (2012) and Hanafizadeh, Keating, and Khedmatgozar (2014), Scopus had purest and most reliable information for journal evaluation. The citation analysis is the most commonly used method to measure the importance of a publication. The mechanism of citation analysis is to count the number of times a journal paper is cited by other papers (Ding \& Cronin, 2011; Xu et al., 2018). Table 3 indicates the citation and citation rank of the journals. Concentrating only on the 91 final papers, which were selected, it was spotted that highest cited journals related to the link between CSR 
and share price were Journal of Business Ethics followed by Journal of Banking and Finance. In general, however, the findings of the top-cited journal were strongly consistent in terms of the top half of the table with the top three, having the same results in both analyses.

Table 2 Frequency of articles published by the journal

\begin{tabular}{|l|c|c|}
\hline \multicolumn{1}{|c|}{ Journal Name } & Number of Articles & Percentage \\
\hline Sustainability (Switzerland) & 14 & $34 \%$ \\
\hline Journal of Business Ethics & 8 & $20 \%$ \\
\hline Corporate Ownership and Control & 3 & $7 \%$ \\
\hline Managerial Finance & 2 & $5 \%$ \\
\hline Social Responsibility Journal & 2 & $5 \%$ \\
\hline Journal of Corporate Finance & 2 & $5 \%$ \\
\hline South African Journal of Economic and Management Sciences & 2 & $5 \%$ \\
\hline Journal of Banking and Finance & 2 & $5 \%$ \\
\hline Investment Analysts Journal & 2 & $5 \%$ \\
\hline International Review of Financial Analysis & 2 & $5 \%$ \\
\hline Applied Economics & 2 & $5 \%$ \\
\hline
\end{tabular}

Table 3 Analysis of a journal based on Citation

\begin{tabular}{|c|c|c|c|}
\hline Journal Name & $\begin{array}{c}\text { Number of } \\
\text { Articles }\end{array}$ & $\begin{array}{c}\text { Citation } \\
\text { (Total Cited) }\end{array}$ & $\begin{array}{c}\text { Citation } \\
\text { Rank }\end{array}$ \\
\hline Sustainability (Switzerland) & 14 & 61 & 3 \\
\hline Journal of Business Ethics & 8 & 184 & 1 \\
\hline Applied Economics & 2 & 14 & \multirow{3}{*}{9} \\
\hline Journal of the Academy of Marketing Science & 1 & 14 & \\
\hline Journal of Corporate Finance & 2 & 14 & \\
\hline Journal of Banking and Finance & 2 & 123 & 2 \\
\hline Journal of International Business Studies & 1 & 49 & 4 \\
\hline Accounting and Business Research & 1 & 38 & 5 \\
\hline Pacific Accounting Review & 1 & 25 & 6 \\
\hline Journal of Marketing & 1 & 24 & 7 \\
\hline International Journal of Managerial Finance & 1 & 17 & \multirow{2}{*}{8} \\
\hline Review of Managerial Science & 1 & 17 & \\
\hline Social Responsibility Journal & 2 & 12 & \multirow{2}{*}{10} \\
\hline International Review of Financial Analysis & 2 & 12 & \\
\hline British Accounting Review & 1 & 11 & \multirow{2}{*}{11} \\
\hline Journal of Accounting Research & 1 & 11 & \\
\hline Economics and Sociology & 1 & 10 & \multirow{2}{*}{12} \\
\hline Investment Analysts Journal & 2 & 10 & \\
\hline $\begin{array}{l}\text { South African Journal of Economic and Management } \\
\text { Sciences }\end{array}$ & 2 & 9 & 13 \\
\hline Corporate Ownership and Control & 3 & 6 & 14 \\
\hline Managerial Finance & 2 & 4 & 15 \\
\hline
\end{tabular}




\subsection{Distribution based on the country}

The distribution of papers based on country of publication is important in determining a worldwide state of the investigation in the topic and illustrates the overall maturity of the literature across the globe (Alshehhi, Nobanee, \& Khare, 2018). Figure 4 indicates that the US ranked as top country followed by Korea, Indonesia and China. Moreover, the US falls in developed economies, which shows that the papers published on the link relationship between CSR and share price have given more important in developed countries. Generally, the quantity of papers published from developing countries is significantly less as compared to developed countries, even though some of the developing countries are observing the highest rate of growth in terms of papers published.

Figure 4 Distribution based on the country of publication

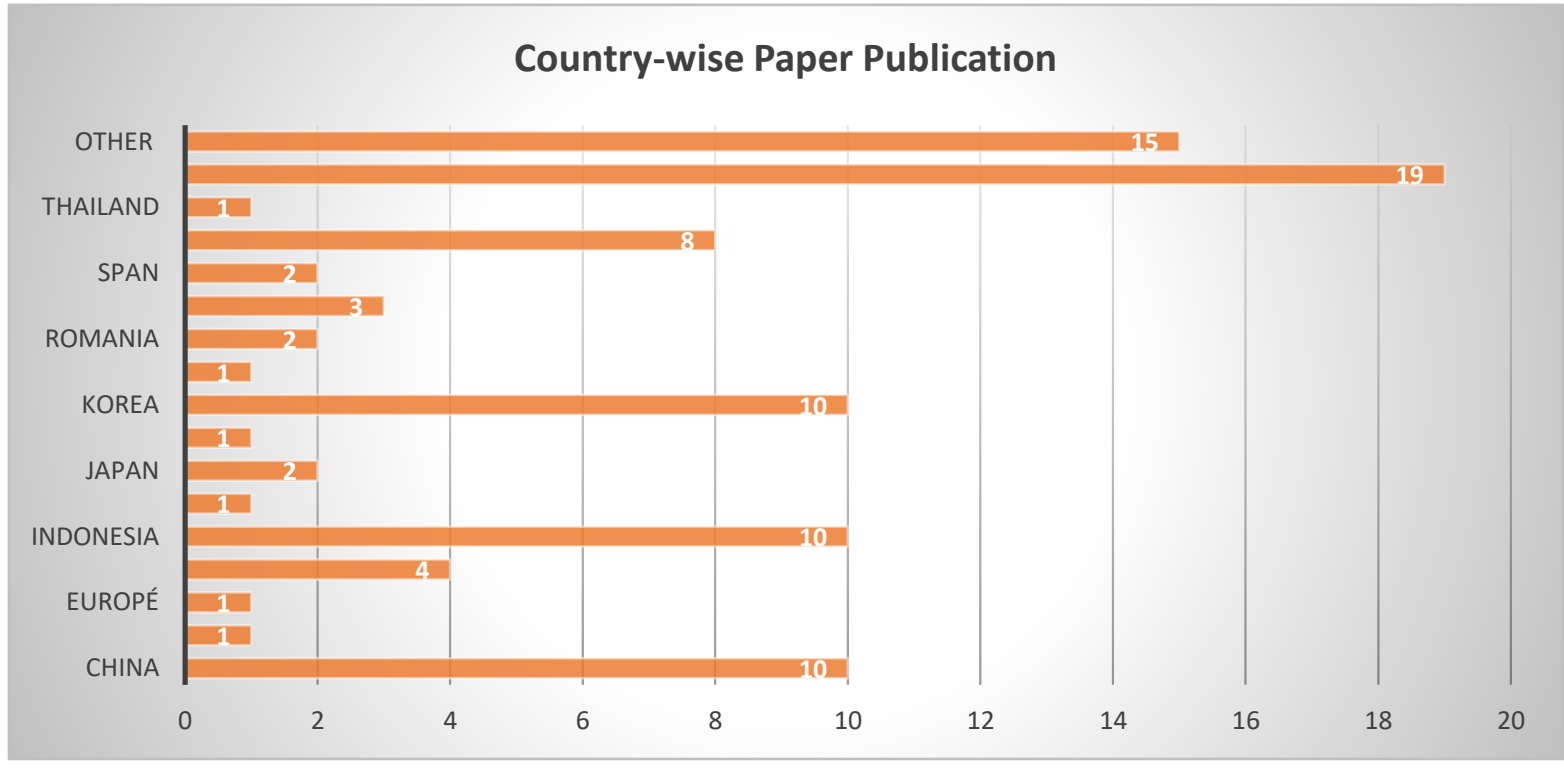

\subsection{Distribution based on publication}

Figure 5 reflects the type of publication, whether the type of paper is journal, conference or editorial. The trend of publishing papers in journal is top-rated (91\%) followed by conference (8\%) from the year 2014 to 2019 on the topic link between CSR and share price. This is due to the fact that information and findings of the articles published in the journal are given more importance by academics and practitioners (Nord \& Nord, 1995; Hanafizadeh et al., 2014).

Figure 5 Distribution based on the type of publication

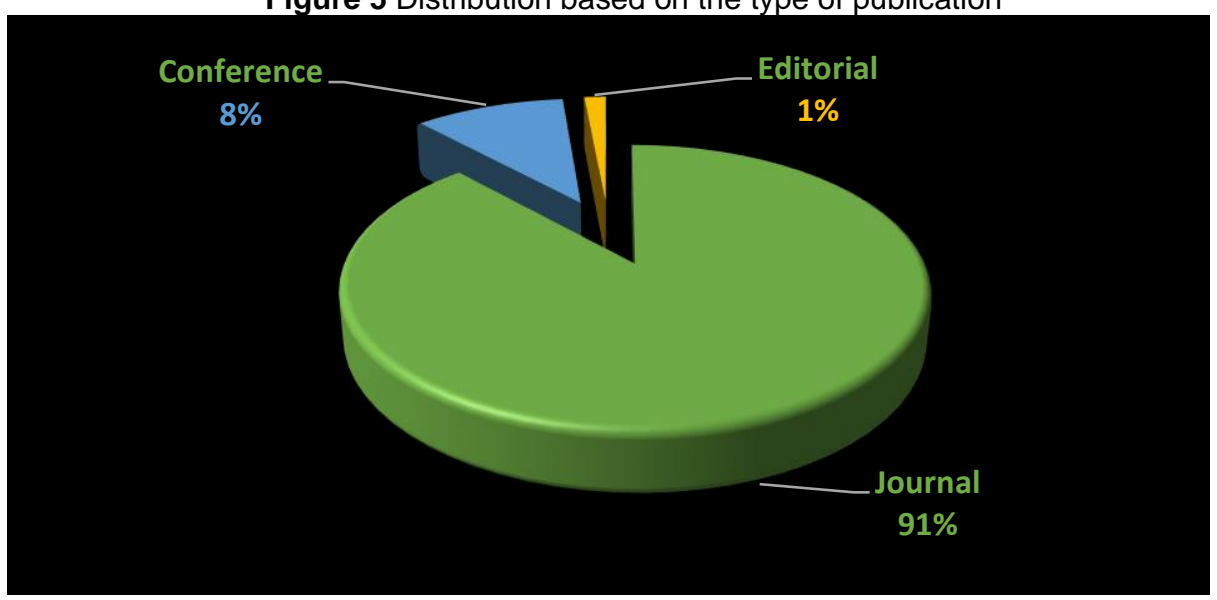




\subsection{Bibliometric analysis of included studies}

We conducted a detailed bibliometric analysis of selected 91 studies based on two fundamental parameters. The first one is text mining to pinpoint the major keywords (terms) that are mostly studies together. This provides us with the concept of clustering the key research areas in the field. We used VOS-viewer (version 1.6.15) software for bibliometric analysis. A total of 160 author keywords was documented, among which 113 used only once, 27 keywords occurred twice, 10 were used three times and 12 keywords occurred more than three times. After re-labelling synonymic single terms and congeneric phrases, 49 terms met the threshold of minimum 2 occurrences for the mapping in VOSviewer. Figure 6 reveals the outcomes of text incidence on the basis of co-occurrence of the correlated keywords. Each circle in the figure indicates a keyword in the dataset. The higher the number of author keywords co-occurred (used), the closer they are placed on the map. The findings revealed that there were 8 major clusters represented by circle colours, which signify different keywords used in 91 included studies. The most prominent is a red cluster, which shows that corporate social responsibility (CSR) was frequently confronted keyword with 86 occurrences and 179 links to other keywords, which can be summarized as stock market performance (blue labelled), shareholder's wealth (yellow labelled), firm performance (purple labelled), corporate governance (green labelled), earnings management (brown labelled) and stock price crash risk (light blue labelled).

Figure 6 Bibliometric map created based on author keywords co-occurrence using network visualization of VOSviewer (Minimum occurrences of a keyword are set to two)

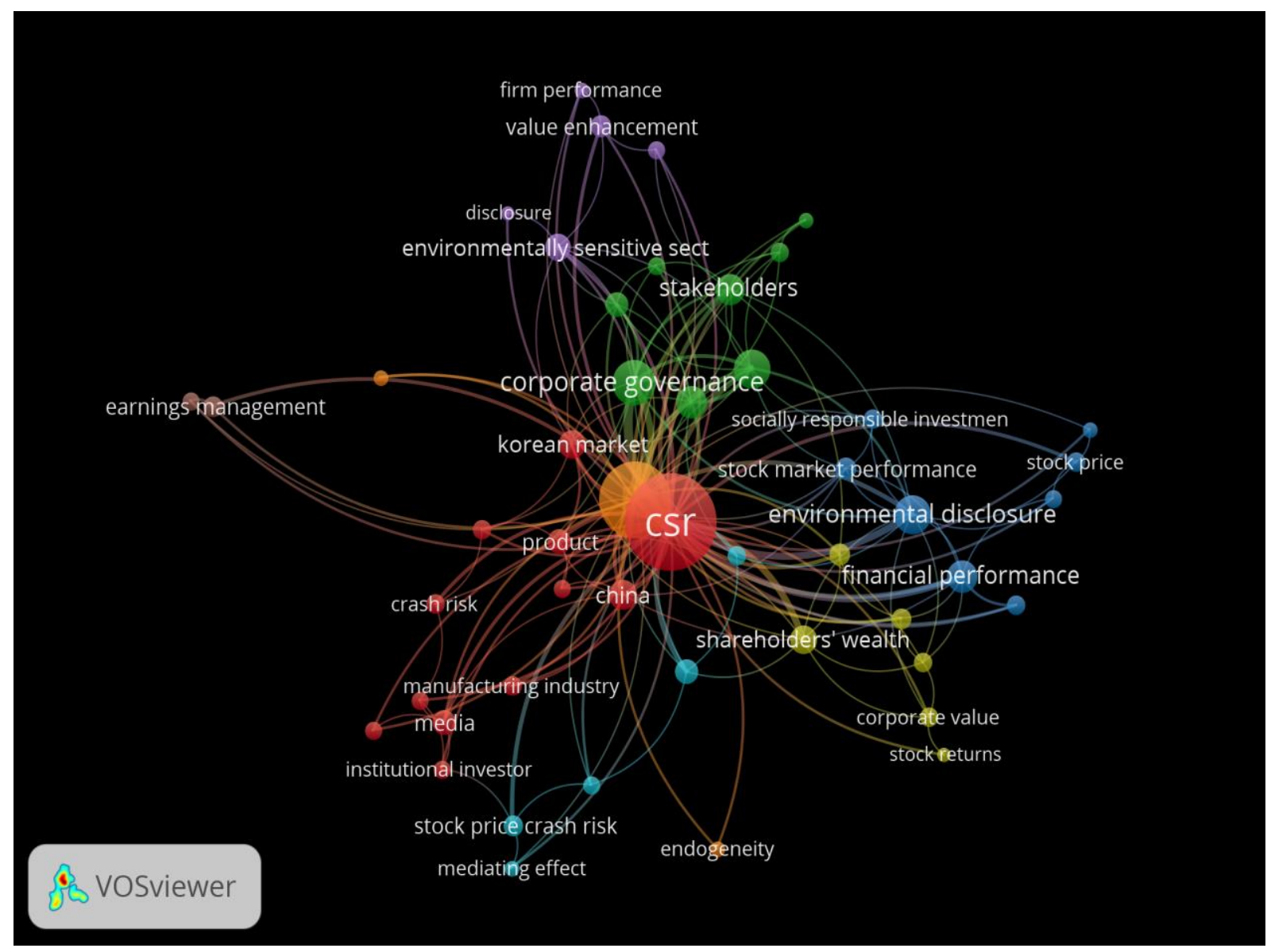

In this regard, the second significant analysis is to examine the countries' collaborative attempts to find alternatives to the issues. The findings in Figure 7 showed that United States (US) followed by was the most associated countries in terms of collaborative research, which linked to 11 countries. The list was followed by New Zealand ( 6 links), South Africa ( 5 links), India (4 links), Australia ( 2 links), Thailand (1 link), and others. It was also revealed that $2 / 3$ of the listed countries had an international collaboration in terms of publications with less than 10 countries based on 91 included studies. 
Figure 7 Bibliometric map Bibliometric map created based on co-authorships with network visualization mode of VOSviewer

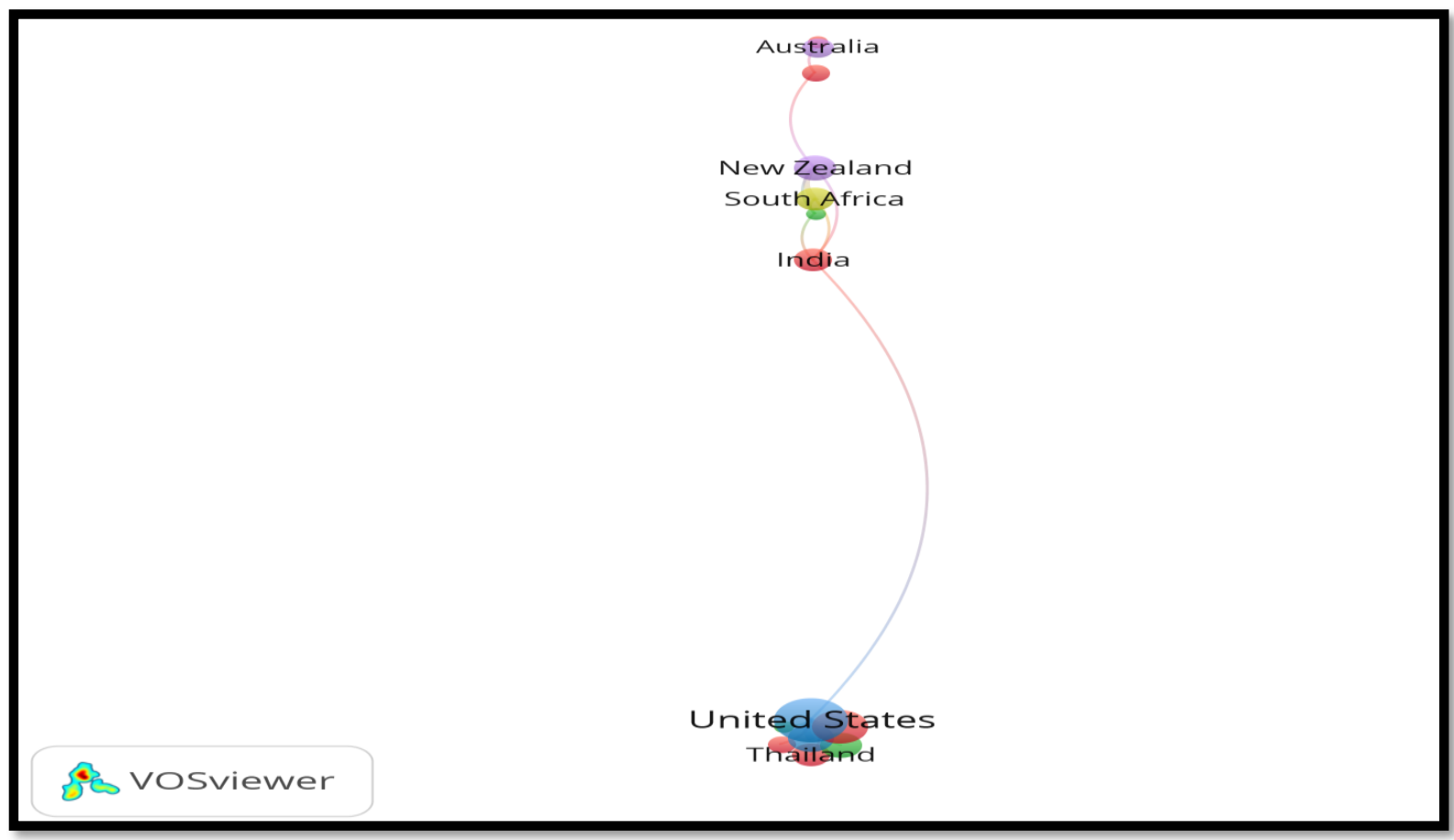

\section{Conclusion}

The basic purpose of this article was to assess the relationship between corporate social responsibility and share price and draw a holistic picture of existing literature related to the subject. In order to achieve this objective, a systematic review was conducted on a specific topic with 91 papers as a sample published from 2014 to 2019. After a thorough examination of these articles, the studies were classified into three groups based on methods i.e. qualitative, quantitative and review studies. Subsequently, the papers were analysed according to the number of papers published per year, which shows an increasing trend over the years, specifically from 2016 to 2019, indicating 87\% of the total articles. In addition, the investigation was carried out based on source journal, country and type of paper. The findings of these analyses were discussed in this paper, which was:

- The importance of this topic is likely to continue in future.

- The quantitative nature of studies was seemed to be dominant over the past year as compared to the other two groups.

- The key journal giving most attention to this topic is the Journal of Business Ethics based on citation rank.

- The top three countries in which the majority of research undertaken on this topic are US, Korea and Taiwan.

- The researchers and practitioners mostly like to publish their research work in journals.

- The countries the US and New Zealand have a greater number of publications in terms of international collaborative research.

- The several areas like corporate governance, shareholder's wealth etc. are currently the wellexplored with CSR.

From the above findings and analysis, some key research opportunities and gaps have been identified for future attention, which includes: 
- The link between CSR and share price should be investigated in developing economies particularly Pakistan, Bangladesh, Thailand and other, as these are the main markets attracting corporations to set up their industries.

- As most of the studies are performed focusing non-financial firms, so conducting additional studies among financial firms and other sectors, will be an addition to the body of literature.

- Different research methodologies can be applied to measure the relationship on the specific subject.

- Different moderating variables like firm size, economy and industry type can be inspected in a different context to extend the applicability of the research.

- Other countries like Thailand can broaden their research collaborations.

- The newly investigated areas (e.g., earnings management, endogeneity etc.) with CSR are some potential hot topics for future studies.

The current study has a couple of limitations that needs great attention. Firstly, the only objective of this article is to measure the link between CSR and share price. However, other issues related to this topic in the body of literature were ignored. Secondly, the selected articles in this review are limited to only the Scopus database and the time boundaries described above. Further research could consider including scholarly articles from other sources like the web of science etc. and also increasing time period, which can give more interesting findings on the specific subject. Third, the present study only included studies from 2014 to 2019. For better generalization, more publications can be used in prospective studies with a longer duration. To pinpoint the new issues and patterns relevant to this research topic, it is significant to duplicate or repeat the current quantitative study by including more studies on given area of research. Lastly, this article used only one software VOSviewer, other bibliometric analysis instruments could be utilized for future studies.

\section{References}

1. Alshehhi, A., Nobanee, H., \& Khare, N. (2018). The impact of sustainability practices on corporate financial performance: Literature trends and future research potential. Sustainability, 10(2), 494.

2. Derwall, J., Koedijk, K., \& Ter Horst, J. (2011). A tale of values-driven and profit-seeking social investors. Journal of Banking \& Finance, 35(8), 2137-2147.

3. Ding, Y., \& Cronin, B. (2011). Popular and/or prestigious? Measures of scholarly esteem. Information processing \& management, 47(1), 80-96.

4. Dornean, A., \& Oanea, D. (2016). The impact of CSR on Company's stock price: evidence from Bucharest stock exchange. Paper presented at the The Proceedings of the 27th International Business Information Management Association Conference, Innovation Vision 2020: From Regional Development Sustainability to Global Economic Growth.

5. Dornean, A., \& Oanea, D. C. (2017). CSR and Company's Stock Price. A Comparative Evidence from Bucharest Stock Exchange. EuroEconomica, 36(1).

6. Economist Intelligence Unit. (2005). The importance of corporate responsibility. Retrieved August, 20, 2008.

7. El Ghoul, S., Guedhami, O., Kwok, C. C., \& Mishra, D. R. (2011). Does corporate social responsibility affect the cost of capital? Journal of Banking \& Finance, 35(9), 2388-2406.

8. Goss, A., \& Roberts, G. S. (2011). The impact of corporate social responsibility on the cost of bank loans. Journal of Banking \& Finance, 35(7), 1794-1810.

9. Hanafizadeh, P., Keating, B. W., \& Khedmatgozar, H. R. (2014). A systematic review of Internet banking adoption. Telematics and informatics, 31(3), 492-510. 
10.Hanafizadeh, P., \& Khedmatgozar, H. R. (2012). The mediating role of the dimensions of the perceived risk in the effect of customers' awareness on the adoption of Internet banking in Iran. Electronic Commerce Research, 12(2), 151-175.

11.Hao, D., Qi, G., \& Wang, J. (2018). Corporate social responsibility, internal controls, and stock price crash risk: The Chinese stock market. Sustainability, 10(5), 1675.

12.Kim, Y., Park, M. S., \& Wier, B. (2012). Is Earnings Quality Associated with Corporate Social Responsibility? The Accounting Review, 87(3), 761-796. doi:10.2308/accr-10209

13.Kim, Y., \& Statman, M. (2012). Do corporations invest enough in environmental responsibility? Journal of Business Ethics, 105(1), 115-129.

14.Lee, D. D., \& Faff, R. W. (2009). Corporate Sustainability Performance and Idiosyncratic Risk: A Global Perspective. Financial Review, 44(2), 213-237. doi:10.1111/j.1540-6288.2009.00216.x

15.Liberati, A., Altman, D. G., Tetzlaff, J., Mulrow, C., Gøtzsche, P. C., loannidis, J. P., . . Moher, D. (2009). The PRISMA statement for reporting systematic reviews and meta-analyses of studies that evaluate health care interventions: explanation and elaboration. PLoS medicine, 6(7), e1000100.

16.Myšková, R., \& Hájek, P. (2019). Relationship between corporate social responsibility in corporate annual reports and financial performance of the US companies. Journal of International Studies, 12(1).

17.Nguyen, P.-A., Kecskés, A., \& Mansi, S. (2017). Does corporate social responsibility create shareholder value? The importance of long-term investors. Journal of Banking \& Finance.

18.Nord, J. H., \& Nord, G. D. (1995). MIS research: journal status assessment and analysis. Information \& Management, 29(1), 29-42.

19.Prieto, A. B. T., Shin, H., Lee, Y., \& Lee, C. W. (2020). Relationship among CSR initiatives and financial and non-financial corporate performance in the ecuadorian banking environment. Sustainability, 12(4), 1621.

20.Khan, N., \& Qureshi, M. (2020). A systematic literature review on online medical services in Malaysia.

21.Raza, H., Ramakrishnan, S., Gillani, S. M. A. H., \& Ahmad, H. (2019). A theoretical review of association between financial sustainability and share price. Asia Proceedings of Social Sciences, $3(2), 41-43$.

22.Saunders, M., Lewis, P., \& Thornhill, A. (2009). Research methods for business students (5 uppl.). Harlow: Pearson education limited.

23.Tranfield, D., Denyer, D., \& Smart, P. (2003). Towards a methodology for developing evidenceinformed management knowledge by means of systematic review. British journal of management, 14(3), 207-222.

24.Van Eck, N., \& Waltman, L. (2020). Manual for VOSviewer version 1.6.15. CWTS Meaningful Metrics. Universiteit Leiden.

25.Van Horne , J. C. (2002). Financial Management \& Policy, 12/E: Pearson Education India.

26.Walsh, J., \& Margolis, J. (2001). People and profits: the search for a link between a company's social and financial performance: Mahwaj, NJ: Lawrence Erlbaum Assoc.

27.Xu, X., Chen, X., Jia, F., Brown, S., Gong, Y., \& Xu, Y. (2018). Supply chain finance: A systematic literature review and bibliometric analysis. International Journal of Production Economics. 